\title{
Foreword
}

\section{Peter McPherson}

When I returned to Michigan State University (MSU) as President in 1993, I was determined to continue and enhance the long-standing tradition of international involvement that had characterized the University largely as the result of initiatives instituted by John Hannah in the 1950s. Of course faculty, led by people like Max Kreinin, had similar aims and indeed had worked effectively to maintain MSU as a place where the international community and American academia came together. It is no wonder, then, that Professor Kreinin and I came to collaborate on a number of projects in recent years. One of these was the book, Building a Partnership: The Canada-United States Free Trade Agreement (MSU Press, 2000), which stemmed from a major conference that we organized on the subject at MSU. Thus it is a particular pleasure to have this opportunity to join his esteemed colleagues and students in recognizing Max Kreinin's extraordinary career and impact.

For more than 45 years, Professor Kreinin has exemplified the ideal of a faculty member at a research-based, land-grant university. He has been a dedicated teacher of students at all levels. Thousands of MSU students - from freshmen studying economics at the introductory level to the most advanced graduate students seeking the intricacies of trade policy - have benefited from his engaging, insightful and challenging classes. And even beyond MSU, Max has extended his teaching impact through his leading textbooks and service around the world as a visiting professor.

Professor Kreinin - as is reflected by the work reported in this volume has also been an internationally recognized scholar whose research and written work has informed both the economics and finance professions as well as the world of economic policy. Most of this research has focused on the empirical foundations of international trade and finance policy. I understand that his publications are so numerous and significant that he has been one of the most cited authors in economics. The combination of Max's research productivity and teaching excellence serves as a reminder that these two aspects of academic life can - and should - be complementary.

Importantly for a university with the history and objectives of MSU, Max has always been committed to sharing his expertise outside the narrow academic community. For example, he has served as the past president of the Inter- 
national Trade and Finance Association and has been a consultant to many institutions, including the United Nations, the US Department of State and the US Department of Commerce. Whether working with the US government, other nations, international organizations, other universities, or the media, he has recognized the importance of transmitting his knowledge, understanding and ideas to others. Thus Max's interests and professional involvement have advanced Michigan State's own international perspective and activity.

My congratulations and thanks to Michael Plummer for organizing and coordinating the conference and this volume and to all of the participants for their excellent contributions.

Peter McPherson, President Michigan State University, East Lansing 